\title{
A Comparative Study on Mechanical Properties of Carbon and Kenaf Composites via Vacuum Infusion Technique
}

\author{
Ikhwan Yusuff, Norshahida Sarifuddin*, Afifah Mohd Ali, \\ Farah Diana Mohd Daud and S. Norbahiyyah \\ Department of Manufacturing and Materials Engineering, \\ Kulliyyah of Engineering, International Islamic University Malaysia, \\ 53100 Kuala Lumpur, Malaysia \\ "Corresponding author: norshahida@iium.edu.my
}

Published online: 30 June 2020

To cite this article: Ikhwan Yusuff, Norshahida Sarifuddin, Afifah Mohd Ali, Farah Diana Mohd Daud and S. Norbahiyyah (2020). A comparative study on mechanical properties of carbon and kenaf composites via vacuum infusion technique. Journal of Engineering Science, 16(1), 97-107, https://doi.org/10.21315/jes2020.16.1.7.

To link to this article: https://doi.org/10.21315/jes2020.16.1.7

\begin{abstract}
The growth of polymer-based composites from either synthetic or natural fibres, especially carbon and kenaf fibres as reinforcement, has gained major interest in many pieces of research. However, only a little attention has been made that compared the mechanical performances of these developed composites based on previous studies. In fact, this comparative study is essential to identify the mechanical gaps between synthetic and natural fibres. Thus, the current work is aiming to provide a comparative study on mechanical properties of manufactured composite materials from both synthetic and natural fibres in which carbon and kenaf fibres were used as reinforcing agents, whereas epoxy resin acts as a matrix phase that fabricated via vacuum infusion method. The thickness and fibre loadings of fabricated composite materials were fixed at $3 \mathrm{~mm}$ and $40 \mathrm{vol} . \%$, respectively. The investigations focused on the mechanical performances of carbon and kenaf composites under tensile and flexural tests. The result shows that tensile and flexural strengths for carbon composite were attained at 399.05 MPa and 362.29 MPa, respectively. Meanwhile, for kenaf composite, the tensile strength was gained at 77.28 MPa, whereas, the flexural strength was obtained at 61.24 MPa.
\end{abstract}

Keywords: carbon composite, kenaf composite, mechanical properties, vacuum infusion 


\section{INTRODUCTION}

For many years, fibre-reinforced composites gained prominent attention to be adopted in a wide range of applications due to its ability to display superior strength and modulus that are comparable to traditional metallic materials. ${ }^{1}$ Fibre-reinforced polymer composites one of the most utilised materials in many engineering components. Polymer composites from synthetic fibres such as carbon, glass, and kevlar successfully implemented in many structural engineering applications such as automotive, marine, aerospace, and construction. ${ }^{2,3}$ The selection of these fibres due to the outstanding appearance of its properties such as excellent mechanical strength, durability, good corrosion resistance as well as high toughness. ${ }^{4,5}$ Due to these excellent attributes, researchers have come out with many efforts that investigate the performances of synthetic-based composites. For example, the tensile strength of continuous carbon composite manufactured using fused filament fabrication was found in the range of $450 \mathrm{MPa} .{ }^{6}$

Recently, the development of composite materials from natural fibres such as kenaf, jute, bamboo and empty fruit bunch (EFB) also rapid growth in many pieces of research. ${ }^{7,8}$ Availability and also categorised as renewable resources make natural fibres become the subject of interest by many researchers. ${ }^{9}$ Moreover, the behaviour of natural fibre that can naturally biodegrade becomes another reason in utilising natural fibres as a reinforcement. Amongst the available natural fibres, fibre extracted from hibiscus cannabinus (kenaf fibre) has shown their potential to be adopted as reinforcement in polymeric composites. Several studies have been made on mechanical properties of kenaf composites. El-Shekeil et al. ${ }^{10}$ investigated the effect of fibre contents on the mechanical properties of kenaf composites. They have found that the tensile and flexural properties of kenaf composites decrease while increasing the kenaf content from $20 \%$ to $40 \%$. Mahjoub et al. evaluated the effect of surface treatment on the tensile strength of kenaf composites. ${ }^{11}$ They reported that the introduction of surface treatment with $5 \%$ of sodium hydroxide $(\mathrm{NaOH})$ on the surface on kenaf fibre tends to improve the tensile strength of fabricated kenaf composite.

Various sorts of processing techniques available to produce these types of composites. The conventional hand layup method is considered the oldest fabrication technique in fabricating fibre reinforced composites. ${ }^{12}$ Latest, vacuum infusion was introduced as a modern processing technique. This method capable to produce composite materials with excellent adhesion behaviour between fibre and matrix phases. ${ }^{13}$ 
Yet, only limited work available that compared the mechanical properties of kenaf composites with synthetic-based composites. Thus, the current research performing a comparative study on the mechanical properties of kenaf composites and carbon composites. These composite materials were fabricated using a vacuum infusion method and subjected to tensile and flexural tests. Other than that, scanning electron microscope (SEM) and optical microscope were used to observe the tensile fractured and flexural modes of failures.

\section{EXPERIMENTAL}

\subsection{Materials}

Woven twill weave pattern carbon fibre supplied by Vestech Technology Services, Malaysia. This fibre has a density of $1.77 \mathrm{~g} \mathrm{~cm}^{-3}$ and a thickness of $0.28 \mathrm{~mm}$ with a tensile strength of 1,380 MPa to 2,070 MPa. Kenaf fibre in a form of fine fabric attained from SBJ Innovation Technology Service, Malaysia with a density of $1.22 \mathrm{~g} \mathrm{~cm}^{-3}$ and thickness of $0.22 \mathrm{~mm}$. The viscous epoxy resin and hardener (INF212) obtained from Castmech Technologies Sdn. Bhd., Malaysia. This matrix resin has a density of $1.122 \mathrm{~g} \mathrm{~cm}^{-3}$ and tensile strength of $78 \mathrm{MPa}$. Table 1 shows the details raw materials.

Table 1: Details of raw materials (data adapted from suppliers' data base).

\begin{tabular}{lllccc}
\hline Raw material & Supplier & Appearance & $\begin{array}{l}\text { Density } \\
\left(\mathrm{g} \mathrm{cm}^{-3}\right)\end{array}$ & $\begin{array}{c}\text { Tensile strength } \\
(\mathrm{MPa})\end{array}$ & Thickness \\
\hline Carbon fibre & $\begin{array}{l}\text { Vestech Technology } \\
\text { Services }\end{array}$ & $\begin{array}{l}2 \times 2 \text { twill weave } \\
\text { pattern (Woven) }\end{array}$ & 1.77 & $1,380-2,070$ & 0.28 \\
Kenaf fibre & $\begin{array}{l}\text { SBJ Innovation } \\
\text { Technology Service }\end{array}$ & $\begin{array}{l}\text { Plain weave pattern } \\
\text { (Fine fabric) }\end{array}$ & 1.22 & $\sim 200$ & 0.22 \\
$\begin{array}{l}\text { Epoxy resin }+ \\
\text { hardener }\end{array}$ & $\begin{array}{l}\text { Castmech } \\
\text { Technologies Sdn. Bhd. }\end{array}$ & Viscous liquid & 1.122 & 78 & - \\
\hline
\end{tabular}

\subsection{Preparation of Composite Materials}

Both carbon and kenaf composites were fabricated using vacuum infusion method. Fibres were placed on the surface of mould. Peel ply was added above the fibres as a barrier between fibres and vacuum bag. To accelerate the movement of epoxy resin, mesh was located on top of vacuum infusion system. Then vacuum bag was applied that attached with sealant tape in order to seal the system. Vacuum pump was switched on for the first time to remove the trapped air inside the vacuum infusion system. Then, a constant pressure $(-25 \mathrm{kPa})$ was used to infuse 
the resin until this resin completely covered the surface of fibres. To obtain the rigid composite panel, the sample underwent curing process for $24 \mathrm{~h}$ at ambient temperature. Figure 1 shows the schematic and experimental setup for vacuum infusion.
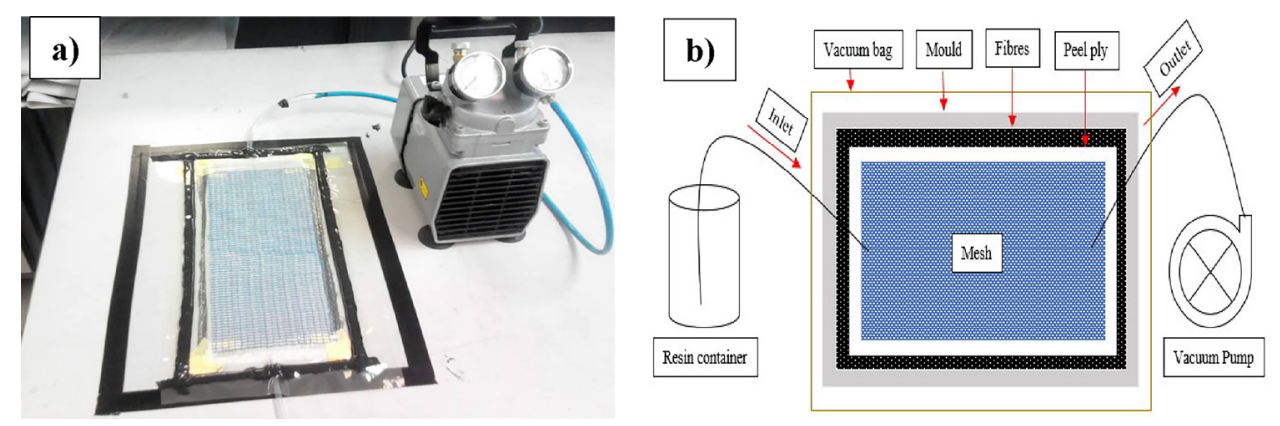

Figure 1: (a) Experimental setup and (b) schematic diagram for vacuum infusion method.

\subsection{Characterisation of Composite Materials}

\subsubsection{Tensile test of composite materials}

Tensile test was performed using the Universal Testing Machine(UTM) (INSTRON 5582) with a crosshead speed of $2 \mathrm{~mm} \mathrm{~min}^{-1}$ and $100 \mathrm{kN}$ load. The sample was cut into a dimension of $250 \mathrm{~mm} \times 25 \mathrm{~mm}$ according to ASTM D3039.

\subsubsection{Flexural test of composite materials}

Flexural test was conducted followed the ASTM D970 standard wherein the sample was prepared by having a dimension of $127 \mathrm{~mm} \times 13 \mathrm{~mm}$. The UTM Instron 5582 was used to perform this test at a crosshead speed of $2 \mathrm{~mm} / \mathrm{min}$.

\subsubsection{Morphological characterisation}

Tensile fractured failures were observed under a scanning electron microscope (SEM, model JOEL JSM-5600). The testing sample was coated with Palladium (Pd) using Quarom SC7620 Sputter Coater at $10 \mathrm{Kv}$ voltage. Flexural modes of failure for crack propagations were observed using an optical microscope (Nikon Measuring Microscope Trinocular Head, model MM-TRF). 


\section{RESULTS AND DISCUSSION}

\subsection{Tensile Properties of Carbon and Kenaf Composites}

Figure 2(a) and 2(b) displays the tensile properties for both fabricated carbon and kenaf composites. As expected, the tensile properties of carbon composite are higher than composites that manufactured using kenaf fibre. From Figure 2(a), the value of tensile strength for carbon composite was found at $399.05 \mathrm{MPa}$ when subjected to tension loads. It indicates that, carbon fibre able to demonstrate excellent load resistance in which it can withstand longer before experiencing permanent damage under tension stress. Meanwhile, tensile strength of kenaf composite was obtained at $77.28 \mathrm{MPa}$ wherein this value is $80.64 \%$ lower than tensile strength of carbon composite. Kenaf fibre not able to provide strong support as a load barrier toward a composite system. However, it should be noted that the tensile strength of current kenaf composite is much higher than the tensile strength of kenaf composite from the previous study wherein this value recorded at $35.6 \mathrm{MPa} .{ }^{14} \mathrm{It}$ is due to the effectiveness of a vacuum infusion method in producing composites with better adhesion characteristic between fibres and matrix phases. To validate this statement, Figure 2(c) and 2(d) represents the surface structure of kenaf and carbon composites under an optical microscope before conducting a tensile test. It can be observed that good laminates of fibres were formed in both carbon and kenaf composites. The same trend can be observed in tensile modulus in which the highest value gained at $16.12 \mathrm{GPa}$ belongs to carbon composite sample while, tensile modulus for kenaf composite obtained at $2.23 \mathrm{GPa}$.

\subsection{Flexural Properties of Carbon and Kenaf Composites}

Figure 3(a) and 3(b) represents the flexural properties both kenaf and carbon composites. It can be perceived that flexural properties exhibit the same behaviour as tensile properties. Composite from carbon fibre shows excellent flexural strength as compared to kenaf composite in which the values were attained at $362.29 \mathrm{MPa}$ and $61.24 \mathrm{MPa}$, respectively. Flexural modulus for carbon composite recorded at $19.86 \mathrm{GPa}$, whereas, the value of flexural modulus for kenaf fibre stated at $4.20 \mathrm{GPa}$. From this result it can deduce that flexural strength of carbon composite is $83 \%$ higher than flexural strength of composite from kenaf fibre. It is due to the capability of carbon fibre to slow down the crack propagation during bending test. Thus, composite from carbon fibre promote a superior endurance for bending stress that consequently result in excellent flexural properties. In the perspective of kenaf composite, weaker kenaf fibre will allow bending loads to penetrate inside the composite body. Therefore, it caused the crack to initiate and propagate easily before experiencing permanent failure. 
(a)

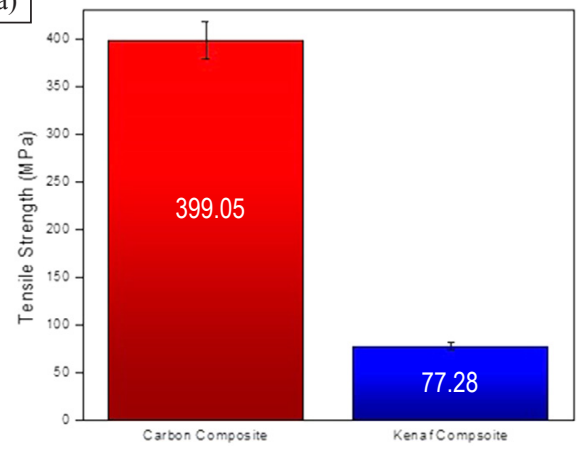

(c)

Good adhesion between kenaf fibers and epoxy

resin
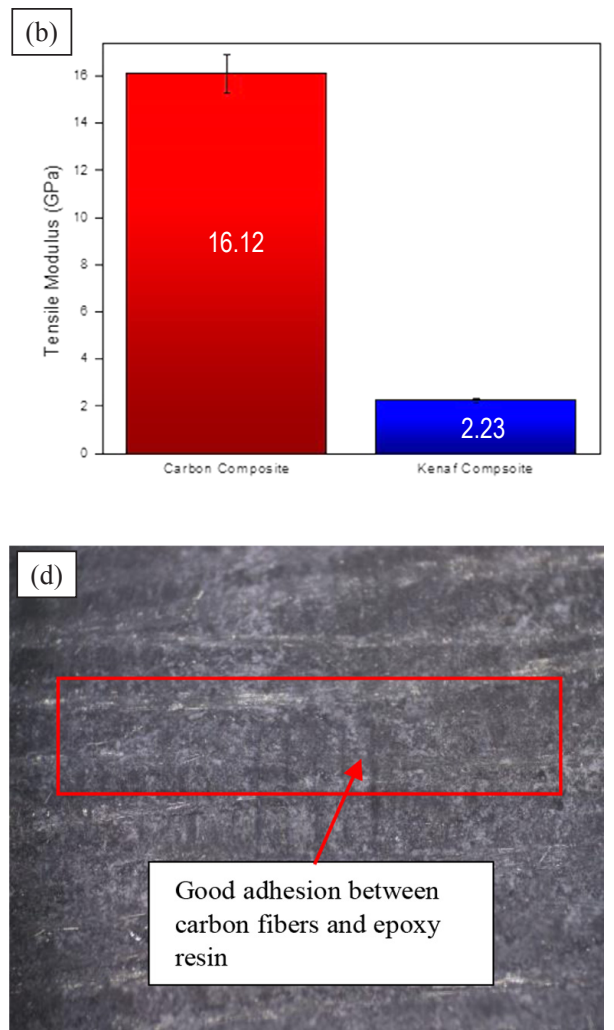

Figure 2: (a) Tensile strength, (b) tensile modulus of carbon and kenaf composites, structures of (c) kenaf composite and (d) carbon composite under optical microscope.

(a)

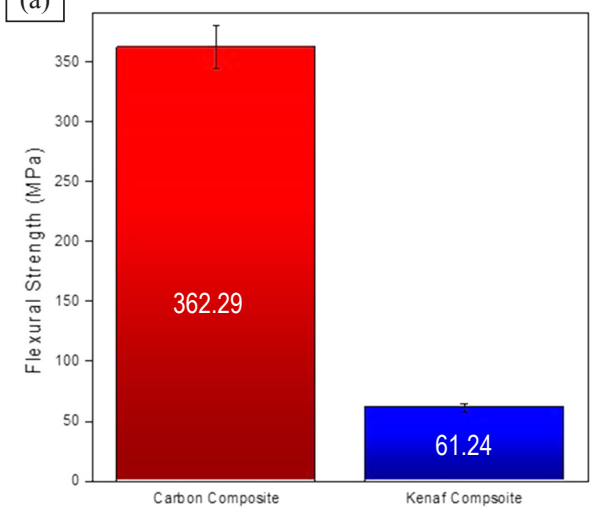

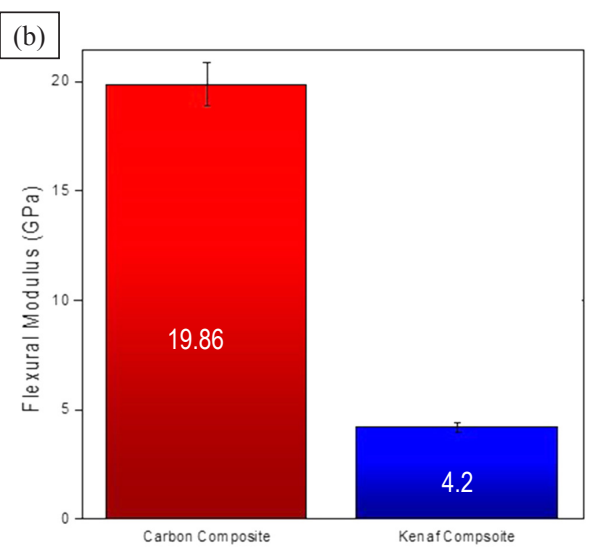

Figure 3: Flexural properties of fabricated kenaf and carbon composites (a) flexural strength and (b) flexural modulus. 


\subsection{Morphological Characterisation}

Morphological characterisation was performed in order to identify the failures that existed after tensile and flexural tests. A SEM was used to examine the tensile fractured failures for both carbon composite and kenaf composite. Figure 4(a-d) shows the SEM micrographs of tensile fractured for kenaf composite. From SEM micrographs, severe fibre breakage can be observed in kenaf composite as shown in Figure 4(a). At a high magnification as shown in Figure 4(c) the present of fibre pull-out can be detected after performing tensile test on kenaf composite samples. This failure occurred due to ineffectiveness of kenaf fibre to resist the high degree of tension loads. Moreover, from Figure 4(d) it can be seen that matrix phase unable to firmly bind and hold kenaf fibres thus, lead to poor mechanical strength of kenaf composite. One of the possible reasons contribute to this phenomenon due to the difference in hydrophobicity of kenaf fibre and epoxy resin. ${ }^{15}$
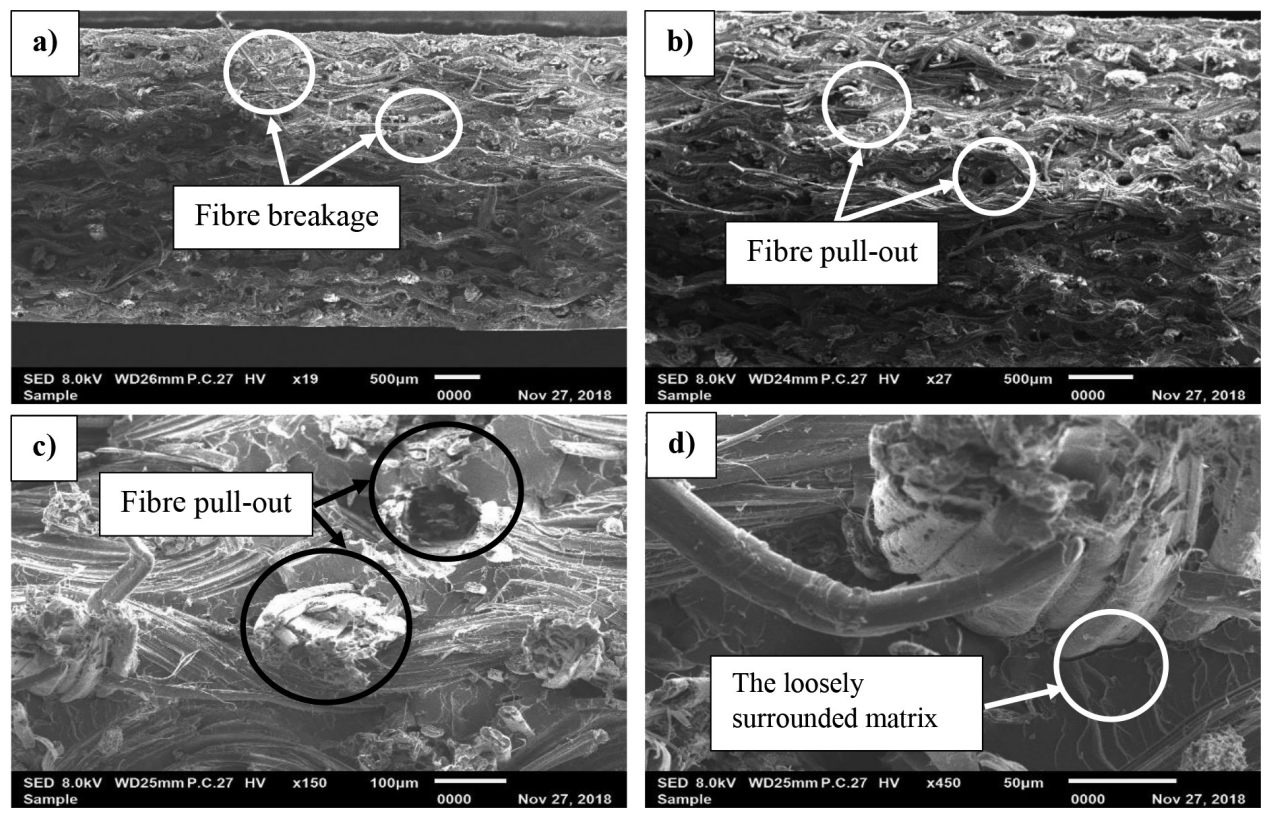

Figure 4: $\quad$ SEM micrographs of tensile fractured failures for kenaf composites at (a) $\times 19$ magnification, (b) $\times 27$ magnification, (c) $\times 150$ magnification and (d) $\times 450$ magnification.

Meanwhile, Figure 5(a-d) shows the SEM micrograph of tensile fractured for carbon composites. From the micrograph, it can be observed the formation of better lamination between layers of carbon fibres. The epoxy matrix fulfils its role to bind carbon fibres effectively. This statement supported by a micrograph 
shown in Figure 5(b) in which good interfacial bonding between fibres and epoxy matrix achieved in carbon composite. Thus, this morphology has validated the mechanical findings that been mentioned in Section 3.1 and Section 3.2. At high magnification, the emergence of fibre pull-out failure can be detected when carbon composite samples subjected to tension loads as shown in Figure 5(c) and 5(d). It should note that this type of failure is a common phenomenon for fibre-reinforced composite materials. ${ }^{16}$
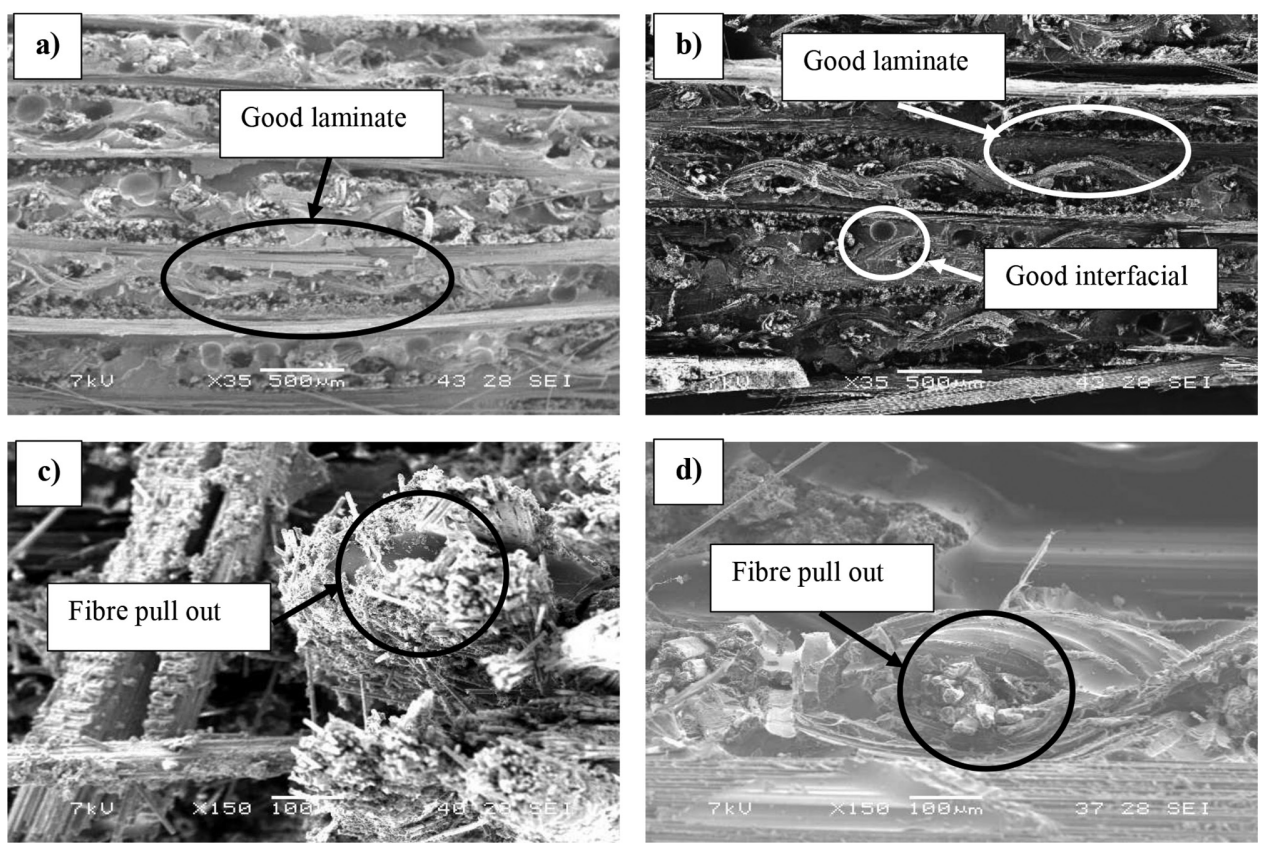

Figure 5: SEM micrographs of tensile fractured for carbon composite at various magnification, (a) $\times 35$ magnification, (b) $\times 35$ magnification, (c) $\times 150$ magnification and $(d) \times 150$ magnification .

The flexural mode of failures was characterised using optical microscope. Figure 6(a) and 6(b) shows the fractography images for carbon and kenaf composites, respectively after exposing to bending loads. From the optical photograph, it can be observed that microcrack starts to initiate at the interface of composite samples, then continue to propagate until the sample be subjected to bending failure. Microcrack can be seen in both kenaf and carbon composites. However, from Figure 6(a), fibre detachment can be found in kenaf composite sample. Other than that, fibre pull-out failures also can be perceived in kenaf composite sample. Meanwhile, sample from carbon composite shows good adhesion bonding between fibres and matrix under bending test as shown in Figure 6(b). 

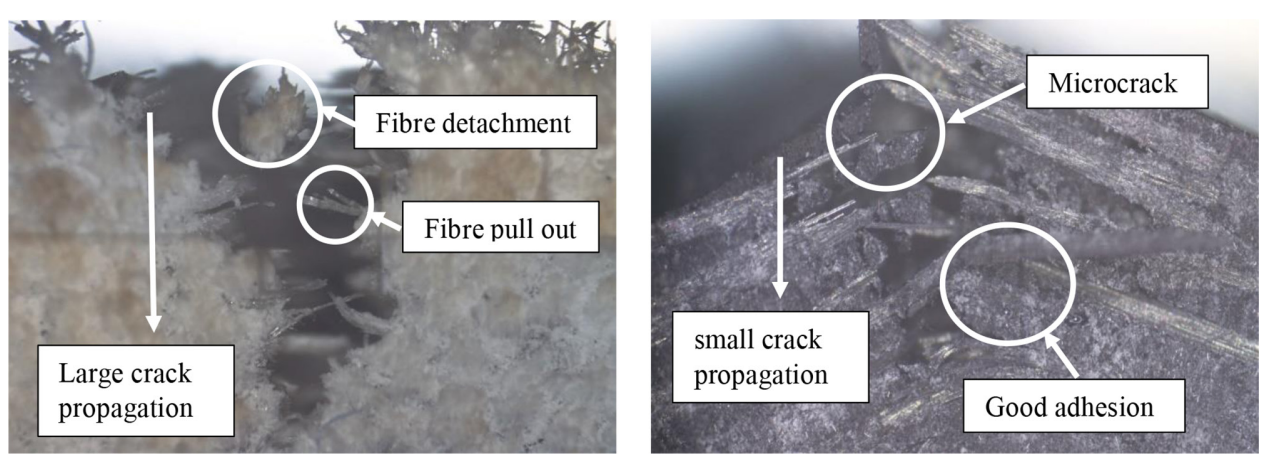

Figure 6: Optical photograph of flexural fractured under optical microscope where, (a) kenaf composite sample and (b) carbon composite sample.

\section{CONCLUSION}

A comparative study on mechanical properties of composite materials from carbon and kenaf have has been successfully carried out. From this study it can be concluded that:

i. Mechanical properties of carbon composite are much greater than kenaf composite. Tensile strength and modulus of carbon composite fabricated via vacuum infusion method were obtained at $399.05 \mathrm{MPa}$ and $16.12 \mathrm{GPa}$, respectively, whereas, tensile strength and modulus for kenaf composite recorded at $77.28 \mathrm{MPa}$ and $2.23 \mathrm{GPa}$.

ii. Flexural properties show the same trend as tensile properties in which both flexural strength and modulus of fabricated carbon composite is higher compared to kenaf composite.

\section{ACKNOWLEDGEMENTS}

The authors would like to acknowledge the Ministry of Higher Education (MOHE) of Malaysia for the granted grant (FRGS 17-033-0599) to fund this research. Kuliyyah of Engineering, International Islamic University Malaysia (IIUM) and Research Management Centre (RMC) IIUM for the support and facilitated this study. 


\section{REFERENCES}

1. Goh, G. D., Dikshit, V., Nagalingam, A. P., Goh, G. L., Agarwala, S., Sing, S. L. et al. (2018). Characterization of mechanical properties and fracture mode of additively manufactured carbon fiber and glass fiber reinforced thermoplastics. Mater. Des., 137, 79-89, https://doi.org/10.1016/j. matdes.2017.10.021.

2. Yeung, K. K. H. \& Reo, K. P. (2014). Mechanical properties of Boron and Kevlar-49 reinforced thermosetting composites and economic implications. Journal of Engineering Science, 10, 19-29.

3. Parandoush, P. \& Lin, D. (2017). A review on additive manufacturing of polymer-fiber composites. Compos. Struct., 182, 36-53, https://doi. org/10.1016/j.compstruct.2017.08.088.

4. Khan, M. I., Abbas, Y. M. \& Fares, G. (2017). Review of high and ultrahigh performance cementitious composites incorporating various combinations of fibers and ultrafines. J. King Saud Univ. Eng. Sci., 29(4), 339-347, https://doi.org/10.1016/j.jksues.2017.03.006.

5. Xu, F., Fan, W., Zhang, Y., Gao, Y., Jia, Z., Qiu, Y. et al. (2016). Modification of tensile, wear and interfacial properties of Kevlar fibers under cryogenic treatment. Compos. B. Eng., 116, 398-405, https://doi.org/10.1016/j.compositesb.2016.10.082.

6. Ma, Y., Ueda, M., Yokozeki, T., Sugahara, T., Yang, Y. \& Hamada, H. (2016). A comparative study of the mechanical properties and failure behavior of carbon fiber/epoxy and carbon fiber/polyamide 6 unidirectional composites. Compos. Struct., 160, 89-99, https://doi.org/10.1016/j. compstruct.2016.10.037.

7. Ramesh, P., Prasad, B. D., \& Narayana, K. (2018). Characterization of kenaf fiber and its composites: A review. J. Reinf. Plast. Compos., 37(11), 731-737, https://doi.org/10.1177/0731684418760206.

8. Sanjay, M. R., Madhu, P., Jawaid, M., Senthamaraikannan, P., Senthil, S. \& Pradeep, S. (2017). Characterization and properties of natural fiber polymer composites: A comprehensive review. J. Clean. Prod., 172, 566-581, https://doi.org/10.1016/j.jclepro.2017.10.101.

9. Ahamad, Z., Razak, A. H. N., Roslan, M. S. N. \& Mosman, N. (2014). Evaluation of kenaf fibres reinforced starch based biocomposite film through water absorption and biodegradation properties. Journal of Engineering Science, 10, 31-39.

10. El-Shekeil, Y. A., Sapuan, S. M., Abdan, K., \& Zainudin, E. S. (2012). Influence of fiber content on the mechanical and thermal properties of Kenaf fiber reinforced thermoplastic polyurethane composites. Mater. Des., 40, 299-303, https://doi.org/10.1016/j.matdes.2012.04.003. 
11. Mahjoub, R., Yatim, J. M., Mohd Sam, A. R., \& Hashemi, S. H. (2014). Tensile properties of kenaf fiber due to various conditions of chemical fiber surface modifications. Constr. Build. Mater., 55, 103-113, https://doi.org/10.1016/j.conbuildmat.2014.01.036.

12. Raji, M., Abdellaoui, H., Essabir, H., Kakou, C. -A., Bouhfid, R. \& Qaiss, A. E. K. (2019). Prediction of the cyclic durability of woven-hybrid composites. In M. Jawaid, M. Thariq and N. Saba (eds.), Durability and life prediction in biocomposites, fibre-reinforced composites and hybrid composites, Cambridge: Woodhead Publishing, 27-62, https://doi. org/10.1016/B978-0-08-102290-0.00003-9.

13. Cardon, L. K., Ragaert, K. J., De Santis, R. \& Gloria, A. (2017). Design and fabrication methods for biocomposites. In L. Ambrosio (ed.), Biomedical composites. Cambridge: Woodhead Publishing, 17-36, https://doi. org/10.1016/B978-0-08-100752-5.00002-0.

14. Hassan, A., Rafiq, M. I. M. \& Ariffin, M. I. Z. (2019). Improving thermal and mechanical properties of injection moulded kenaf fibre-reinforced polyhydroxy-butyrate composites through fibre surface treatment. Bioresources, 14(2), 3101-3116.

15. Zhang, W., Gu, J., Tu, D., Guan, L. \& Hu, C. (2019). Efficient hydrophobic modification of old newspaper and its application in paper fiber reinforced composites. Polymers, 11(5), 842, https://doi.org/10 .3390/polym11050842.

16. Rukavina, T., Ibrahimbegovic, A. \& Kozar, I. (2019). Fiber-reinforced brittle material fracture models capable of capturing a complete set of failure modes including fiber pull-out. Comput. Methods Appl. Mech. Eng., 355, 157-192, https://doi.org/10.1016/j.cma.2019.05.054. 